\title{
Nos becos da Episteme: Caminhos confluentes para uma contra coloniza- ção didática em meio à crise da verdade ${ }^{+}$
}

Em 2019, o editorial do primeiro número do Caderno Brasileiro de Ensino de Física (MOURA, 2019) parte do reconhecimento de problemas contemporâneos brasileiros (os desastres ambientais em Mariana e Brumadinho, o número de ativistas mortos no Brasil, o número de pessoas abaixo da linha da pobreza, o contingenciamento dos investimentos em pesquisa, entre outros) para levantar a seguinte pergunta: a que serve uma Educação em Ciências que ignore a atual conjuntura (ambiental e social) em que vivemos?

Em especial, o caminho apresentado por Moura (2019) exige que a promoção de justiça social passe, necessariamente, pelo comprometimento com a promoção de justiça cognitiva. Isto é, a justiça social também demanda a visibilização e legitimação de práticas e saberes que foram construídos e estabilizados em grupos e contextos distantes da Ciência europeia. Tal visão, em consonância com diferentes vertentes do multiculturalismo, póscolonialismo e, mais especificamente, com as Epistemologias do Sul de Boaventura de Sousa Santos (2019) parece requerer, entretanto, uma revisão do status epistemológico privilegiado que a Ciência quase sempre obteve no contexto da educação científica.

A discussão sobre tal status, ainda que seja interessante do ponto de vista filosófico, transcende os limites da reflexão epistemológica e enseja entrelaçamentos políticos que não podem ser ignorados. Em 2006, o dicionário Oxford anunciou como palavra do ano o termo a pós-verdade, o qual se refere a situações em que o apelo emocional e irracional se sobrepõe aos fatos conhecidos, impactando a opinião pública. De 2006 para cá, muitos são os exemplos em que conhecimentos amplamente estabelecidos e estabilizados pela comunidade científica foram artificialmente controvertidos - criando confusão no público leigo, com mediação, principalmente, das redes sociais.

A pós-verdade e as fake news recolocam, no debate, a importância do estabelecimento de critérios claros e confiáveis para escolher quais conhecimentos são válidos para ser levados em consideração na tomada de decisão pública (o que, em princípio, colocaria a ciência novamente em uma posição privilegiada epistêmica e politicamente). Nesse sentido, se por um lado, é necessário construir uma ecologia dos saberes e promover justiça cognitiva, como defende Moura e como defendemos também, por outro é necessário desenvolver estratégias para nos movermos em meio aos cenários de pós-verdade. O que gostaríamos de apresentar nesse editorial é uma visão histórica mais ampla sobre esse dilema. Acreditamos que, a partir

\footnotetext{
${ }^{+}$In Episteme Alleys: Confluent Paths to a Didactic Counter Colonization in the center of Truth Crisis

* Recebido: novembro de 2019.

Aceito: novembro de 2019.
} 
dessa visão historicamente situada, possamos entender melhor o Ensino de Física contemporâneo e pensar em possíveis caminhos para a educação científica que queremos construir, tendo como objetivo a promoção da justiça cognitiva, sem com isso ceder às confusões criadas pela pós-verdade. Essa discussão também é fruto de debates no contexto internacional, como indica Kampourakis (2019) em editorial da revista Science \& Education.

Tomamos como ponto de partida para esse resgate histórico o ano de 1869, quando o artista e pensador brasileiro Pedro Américo de Figueiredo e Mello defendeu sua tese de doutorado, intitulada La Science et les Systèmes - Questions d'Histoire et de Philosophie Naturelle, em Bruxelas. Na conclusão do trabalho, Pedro Américo sintetizou os resultados de sua análise histórica e epistemológica:

Mediante alguns fatos colhidos da história das belas artes, mostramos quanto o espírito moderno é devedor de seus progressos aos grandes artistas que fundaram o Renascimento e, com ele, a liberdade intelectual; e a ciência nos pareceu fruto da aplicação legítima dessa liberdade em busca do verdadeiro (AMÉRICO, 2001, p. 130).

A visão de Pedro Américo sobre o nascimento da ciência moderna no século XVI traduz o zeitgeist de sua época, no qual a tradição científica é identificada com o ideal de liberdade epistêmica e com a busca pela verdade. Concepção semelhante sobre a ciência pode ser encontrada em obras de Gaston Bachelard (1985) e na descrição de Paul Feyerabend (2011) sobre o mesmo período.

Pensando sobre uma história mais recente da ciência, pode-se dizer que o século XX sediou a ascensão da Ciência Ocidental Moderna (Western Modern Science - WMS) como fonte absoluta de conhecimento. Em especial, as teorias de Verdade por correspondência (POPPER, 1963) desempenharam um papel importante na consolidação da concepção de que a WMS seria capaz de prover um conjunto organizado e seguro de conhecimentos sobre a realidade, como aparece nas propostas do Círculo de Viena. De fato, o sucesso da Mecânica nos séculos precedentes somado ao desenvolvimento da Teoria Eletromagnética e da Termodinâmica, e sua natural participação na revolução industrial e no desenvolvimento da economia capitalista, com todas as transformações sociais advindas disso, impulsionaram o sentimento de que a ciência seria uma grande fonte de progresso e bem-estar social (DECONTO, 2014).

Foi também no século XX, entretanto, que a imagem pública da ciência, e dos ideais epistemológicos e sociais que ela inspirava, começou a ruir. Percebeu-se que a "modernidade" vinha com o alto preço de uma destruição ambiental silenciosa (CARSON, 1994), e o desenvolvimento do armamentismo nuclear revelou que nem só de curiosidade epistêmica vivem os cientistas. Apenas para mencionar um exemplo, Werner Heisenberg (2000), no seu livro Physics and Philosophy, apresenta sua preocupação com as consequências políticas do desenvolvimento da Física Moderna.

A decepção com as implicações sociais e políticas advindas do progresso científico viabilizaram no campo epistemológico a possibilidade de, também, atacar a noção da WMS 
como fonte única, absoluta e segura de conhecimento. Os ataques não foram poucos nem fracos. De fato, mesmo propostas filosóficas mais conservadoras tiveram implicações dramáticas ao status epistemológica da ciência: Popper (1963) mostrou que nenhuma teoria científica pode ser comprovada; Lakatos (1978), que não existe experimento puramente empírico - todo experimento é também teórico; Kuhn (1996), que a ciência, muitas vezes, se organiza de forma tão dogmática quanto uma religião e Feyerabend (1995), que a ciência avança apenas quando seus praticantes adotam posturas irracionais.

Mas esse é só o início da história. Estudiosos da Ciência discutiram o fato de que ciência e política sempre estiveram misturados (SHAPIN; SCHAFFER, 1985), a realidade científica é construída socialmente (KNORR-CETINA, 1981; LATOUR; WOOLGAR, 1986), verdade e falsidade devem ser tratados simetricamente (BLOOR, 1991), a verdade é um efeito do poder (FOUCAULT, 2018), e a realidade está fortemente atada ao discurso (DERRIDA, 1997). Diversos estudos, ademais, revelaram os aspectos mais obscuros e anticientíficos da própria ciência. Alguns autores, a partir de diferentes estudos e por diversos motivos, passam a apresentar a WMS não apenas como Western Modern Science, mas como White Male Science (ciência branca e masculina). Nessa visão, a ciência, assim como a religião, foi o braço forte do colonialismo. Isto é, o discurso de legitimação do colonialismo foi permeado tanto por razões religiosas (salvar as almas dos povos pagãos) como científicas (levar a modernidade aos povos pré-modernos).

A ciência que conhecemos e que ensinamos na escola foi, em sua maior parte, feita ou apresentada como tendo sido construída por homens brancos europeus. Isso significa que a ciência não somente deslegitimou a produção de conhecimento de outros grupos bem como apagou de sua história a contribuição dada por atores de outros espectros étnicos e sociais. Ao deslegitimar outras formas de conhecimento, produzido nas colônias, a WMS provocou o que pode ser denominado de epistemicídio (SANTOS; MENESES, 2009). Não só o conhecimento colonial e feminino foi apagado; mas outras formas de produzir conhecimento e de se relacionar com a natureza e a realidade foram sufocadas em nome de uma monocultura da mente (SHIVA, 2003). Assim, aquela tradição identificada com a liberdade e a verdade, descrita por Pedro Américo, fundiu-se com as estruturas de poder e passou ela mesma a ser um instrumento de dominação. Nesse sentido, pode-se entender que os estudos pós-modernistas e póscolonialistas (apesar de sua imensa diversidade teórica) dialogam no sentido de buscar a legitimação e visibilização de atores e conhecimentos que foram apagados da história oficial. Isso pode exigir, entretanto, como mencionamos no início deste texto, uma revisão sobre o que é a ciência, qual é o seu caráter epistemológico e qual o seu papel na sociedade contemporânea.

No fim da década de cinquenta, C. P. Snow já havia apresentado sua preocupação com relação ao desprezo que as ciências e engenharias sofriam por setores das ciências humanas em seu emblemático livro The Two Cultures (Snow, 1988). Na década de 1970, Fritjof Capra escreveu $O$ Ponto de Mutação (CAPRA, 1998) - discutindo a ideia de que a Física como conhecemos, baseada no pensamento cartesiano (atomista, reducionista e dualista), e suas 
influências em outros setores do conhecimento moderno (saúde, psicologia, economia) estão em crise. Para Capra, entretanto, não devemos abandonar a ciência, mas reconhecer que o nascimento de uma nova Física, emoldurada por concepções ontológicas e epistemológicas afastadas do positivismo lógico, dariam nascimento a uma nova cosmovisão, distante da perspectiva extrativista do patriarcado e do colonialismo (CAPRA, 2006). Tal ideia, posteriormente, foi desenvolvida por Boaventura de Sousa Santos (2008) no final da década de oitenta, imaginando uma aproximação entre as ciências exatas e humanas no que ele chamou de "Paradigma Emergente".

A comunidade científica e os defensores da Verdade, entretanto, parecem não ter simpatizado com as críticas à ciência nem com a possibilidade de aproximação entre ciências humanas e exatas, e a década de noventa deflagrou episódios intensos, que ficaram conhecidos como Science Wars. Em 1996, a revista Social Text publicou um número especial dedicado ao assunto. Um dos artigos publicados nesse número era assinado por David Sokal, físicomatemático, e era intitulado; "Transgressing the Boundaries: Towards a Transformative Hermeneutics of Quantum Gravity” (SOKAL, 1996). Após a publicação do artigo, Sokal escreveu um novo texto informando que havia escrito alguns absurdos no artigo publicado na Social Text e que o artigo não havia passado de um experimento para averiguar se revistas sociológicas publicariam textos sem sentido apenas porque concordavam com as concepções dos editores. Ao longo dos anos, outros cientistas importantes como Steven Weinberg e Steven Pinker também têm se pronunciado em defesa do status privilegiado da ciência. O ideal imaginado, portanto, por pensadores como Capra e Boaventura, no sentido de uma aproximação entre ciências exatas e humanas, parece longe de acontecer.

O século XXI, entretanto, trouxe novos elementos a essa disputa, principalmente com o estabelecimento da pós-verdade. Isso traz, entretanto, consequências muito mais drásticas do que uma disputa filosófica ou um debate entre intelectuais. Apresentamos, recentemente, uma discussão aprofundada sobre questões filosóficas relacionadas à pós-verdade e sobre implicações para a educação em ciências (LIMA; VAZATA; MORAES; OSTERMANN; CAVALCANTI, 2019). Neste artigo, discutimos o fato de que achar um caminho a seguir nos tempos de pós-verdade pode representar a nossa sobrevivência ou não em meio a tantas crises que se alastram atualmente, em especial, a chamada crise do Antropoceno (LATOUR, 2014). Alguns autores culpam o pensamento pós-moderno pelo desenvolvimento da pós-verdade (MCINTYRE, 2018) e, de fato, Bruno Latour, um dos protagonistas das Science Wars, discute o fato de que argumentos da sociologia da ciência estão sendo mobilizados para modificar a opinião pública sobre temas como aquecimento global e uso de combustíveis fósseis (LATOUR, 2004). Recentemente, Bruno Latour reconheceu que no início das Guerras das Ciências o objetivo era atacar o absolutismo epistemológico da ciência, mas, agora, seria necessário resgatar a sua autoridade (VRIEZE, 2017).

O cenário atual, portanto, é o seguinte: a separação entre ciências humanas e ciências exatas, que poderia ter diminuído, parece ter se acentuado ainda mais. Por um lado, temos 
resultados de muitos estudos históricos, sociológicos, culturais, etnográficos que problematizam a natureza da ciência e sua miscigenação com formas de dominação. Por outro lado, temos questões muito claras postas à mesa, cuja resposta pode nos levar à sobrevivência ou à destruição, e sobre as quais a ciência tem algum parecer para oferecer.

Quando os cientistas dizem que a Amazônia está sendo devastada, devemos ou não acreditar na ciência? E quando os cientistas dizem que o aquecimento global tem origem antropogênica? E quando os cientistas dizem que estamos comendo agrotóxicos demais? E quando os cientistas dizem que devemos tomar vacinas? E quando os cientistas dizem que manifestações pacíficas têm mais efeito do que violentas? A resposta, no nosso entendimento, para todas essas perguntas é que a população deve ser capaz de, ouvindo os especialistas, se posicionar criticamente para agir de maneira consciente. Para que isso possa acontecer é necessário que os cientistas estejam dispostos a dialogar com a sociedade a fim de construir pontes entre as diferentes culturas. Os cientistas precisam, mais do que nunca, sair dos seus laboratórios e gabinetes, e as Universidades precisam se abrir para se tornar Pluriversidades (SANTOS, 2019). Há espaço para as ciências na Ecologia dos Saberes, mas, sobretudo, há espaço para o diálogo e para a construção conjunta de saberes e soluções.

Mas de que maneira estas discussões sobre o status da ciência são refratadas para o contexto educacional? Em dois artigos (LIMA; OSTERMANN; CAVALCANTI, 2017; LIMA et al., 2018), discutimos a apresentação de Física Moderna nos livros didáticos aprovados no Plano Nacional do Livro Didático de 2015. Em nossa análise, concluímos que os livros apresentam uma forma de "colonialismo didático", introduzindo temas, estruturas composicionais, estilos, e visões de mundo de forma subserviente aos textos e propósitos didáticos dos bacharelados em física.

A educação científica na Educação Básica é extremamente importante. Ela não pode, entretanto, ser um reflexo pálido da educação bacharelesca. Ademais, no âmbito social, já mostramos em pesquisas anteriores que uma educação focada no conteúdo específico, em detrimento de discussões mais amplas e contextuais sobre conceitos científicos, tende a favorecer a manutenção das desigualdades sociais (NASCIMENTO; CAVALCANTI; OSTERMANN, 2018; NASCIMENTO, 2019). A insurgência de visões absurdas como o terraplanismo, o negacionismo do aquecimento climático, o movimento anti-vacina, o fenômeno da pósverdade e das fake news, são evidências fortes de que nosso ensino científico instrumentalista fracassou terrivelmente.

Precisamos de uma educação verdadeiramente científica e não cientificista. Mas para ser científico (ou seja, em consonância com o ideal de liberdade epistêmica descrita por Pedro Américo) precisamos descolonizar a ciência, a educação, e a educação em ciências - ou seja, precisamos construir uma nova identidade para a Educação Científica da Educação Básica: precisamos de uma contra colonização didática. Para tanto, precisamos ir para fora das me-

\footnotetext{
${ }^{1}$ Usamos o termo contra colonização em consonância com o que é apresentado por Antônio Bispo dos Santos (2015)
} 
trópoles epistemológicas, precisamos ir para os becos. Assim como Conceição Evaristo (2017) nos narra personagens esquecidos nos Becos da Memória, precisamos buscar, nos becos da episteme, novas teorias, novos objetivos didáticos, novas organizações curriculares e escolares. Sobretudo, precisamos ressignificar a nossa relação com a natureza e aprender com os grupos que souberam desenvolver uma vida confluente (SANTOS, 2015). Isso não significa, entretanto, que temos que deixar a ciência de lado. A pergunta a ser feita é a seguinte: como pode a ciência ajudar na construção de um mundo mais social e cognitivamente justo?

Em especial, buscando contribuir para a construção de novos caminhos, no presente número do Caderno Brasileiro de Ensino de Física, apresentamos o artigo "A Filosofia Sistêmica de Fritjof Capra: Um Olhar Ecológico para a Física e para o Ensino de Física" - no qual discutimos a visão Ecológica de Capra e sua marginalização no meio acadêmico. Entendemos que o pensamento de Fritjof Capra pode suscitar reflexões para retomarmos a noção de um Paradigma Emergente, no qual ciências humanas e exatas dialogam e constroem novos caminhos para um mundo mais justo socialmente e em confluência com a natureza.

Para que a educação científica possa de fato ter o potencial de nos ajudar a superar as crises da contemporaneidade, entendemos que precisamos aprender as seguintes lições vindas dos becos da episteme:

I) Pautas nacionais sem perder diálogo com o cenário internacional: A educação científica tem que ser reatada com os problemas reais e concretos da nossa realidade. É necessário construir pautas nacionais e desenvolver expertise nessas áreas estratégicas. Isso não significa, entretanto, abandonar o diálogo com a comunidade internacional. Precisamos investir na diversidade temática da ciência e da educação em ciências. Tal concepção vai ao encontro, por exemplo, do que é discutido hoje no movimento CTS latino-americano (AULER, 2018).

II) Visibilizar atores apagados pela história oficial: Precisamos fazer um esforço para superar a história reducionista da ciência em que poucos homens brancos foram responsáveis por descobertas geniais. Trabalhos recentes na área de educação em ciências têm se apropriado da história cultural da ciência a fim de produzir contra-narrativas à história hegemônica (MOURA; GUERRA, 2016).

III) Legitimar outras formas de ser e conhecer, privilegiando a confluência e a emancipação social: Se a ciência é uma tradição que pode ajudar muito a pensar sobre os problemas contemporâneos, isso não significa que ela é a única. Em especial, existe uma série de conhecimentos tradicionais e conhecimentos desenvolvidos nas lutas sociais, que não são legitimados ou reconhecidos na tradição científica. Quando os conhecimentos têm um potencial emancipatório, seja em relação aos grupos sociais minoritários, ou um potencial de confluência, eles devem ser valorizados e legitimados, formando uma ecologia de saberes (SANTOS, 2019).

IV) Ter responsabilidade política: ter responsabilidade política significa reconhecer que a educação e a ciência são práticas sociais. A escolha dos temas e das abordagens 
sempre implicam um posicionamento axiológico. Nesse sentido, é importante que a educação científica politize-se, trazendo para sala de aula temas de relevância social (NASCIMENTO; LIMA; CAVALCANTI; OSTERMANN, 2019)

V) Transformar divergências em diversidade: diferenças, discordâncias e divergências sempre haverá. Ao invés disso enfraquecer a comunidade de educadores e de pesquisadores em educação em ciência, isso deve nos fortalecer. A divergência deve ser encarada como diversidade (SANTOS, 2015) e, assim, através do constante diálogo, construir possíveis caminhos para uma educação confluente.

Tentamos, ao longo desse rápido resgate histórico, apresentar o panorama epistemológico que serve de cenário para pensarmos sobre a construção da Educação em Ciências e do Ensino de Física. Quisemos mostrar que aprendemos muito e temos muito para aprender com as discussões pós-modernas e pós-coloniais. Isso não pode, entretanto, nos levar a crer que a ciência não pode nos dar resposta nenhuma para as crises que vivemos. Sobretudo, precisamos, mais do que nunca, de uma ciência e de uma educação científica forte e fortemente lastreada em uma cultura política, epistemológica e sociológica que nos permita construir caminhos confluentes e socialmente justos.

Não existe caminho simples para isso. Precisamos investir no diálogo, na solidariedade, na compreensão. Precisamos nos unir. Precisamos transformar divergências em diversidade. Onde encontraremos respostas? Nos becos. Nos becos da memória. Nos becos da episteme.

\section{Referências}

AMÉRICO, P. A Ciência e os Sistemas: Questões de História e Filosofia Natural. 4th ed. João Pessoa: Editora Universitária, 2011.

AULER, D. Cuidado! Um cavalo viciado tende a voltar para o mesmo lugar. Curitiba: Appris., 2018.

BACHELARD, G. The new Scientific Spirit. Boston: Beacon, 1985.

BLOOR, D. Knowledge and Social Imagery. Chicago: The University of Chicago Press, 1991.

CAPRA, F. O Ponto de Mutação. São Paulo: Editora Cultrix, 1998.

CAPRA, F. A Teia da Vida. São Paulo: Editora Cultrix, 2006.

CARSON, R. Silent Spring. Robbisdale: Fawcett Publications, 1994. 
DECONTO, D. C. S. A perspectiva ciência, tecnologia e sociedade na disciplina de Metodologia do Ensino de Física: um estudo na formação de professores à luz do referencial sociocultural. 2014. Dissertação (Mestrado Acadêmico em Ensino de Física) - Universidade Federal do Rio Grande do Sul.

DERRIDA, J. Of Grammatology. Baltimore: The John Hopkins University Press, 1997. v. 87.

EVARISTO C. Becos da Memória. Rio de Janeiro: Pallas, 2017.

FEYERABEND, P. Against the Method. London: Verso, 1995.

FEYERABEND, P. A Ciência em uma Sociedade Livre. São Paulo: Editora UNESP, 2011.

FOUCAULT, M. Microfísica do Poder. Rio de Janeiro: Paz e Terra, 2018.

HEISENBERG, W. Physics and Philosophy. London: Penguin, 2000.

KAISER, D. Pedagogy and the practice of science. Cambridge: The MIT Press, 2006.

KAMPOURAKIS, K. Science, Society, and Scientific Literacy. Science \& Education, v. 28, n. 6, p. 603-604, 2019.

KNORR-CETINA, K. The manufacture of knowledge: an essay on the constructivist and contextual nature of science. London: Elsevier, 1981.

KUHN, T. The structure of Scientific Revolutions (Terceira). Chicago: The University of Chicago Press, 1996.

LAKATOS, I. The Methodology of Scientific Research programmes. Cambridge: Cambridge University Press, 1978. v. 1.

LATOUR, B. Why Has Critique Run out of Steam? From Matters of Fact to Matters of Concern. Critical Inquiry, v. 30, n. 2, p. 225-248, 2004.

LATOUR, B. Para distinguir amigos e inimigos no tempo do Antropoceno. Revista de Antropologia, v. 57, n. 1, p. 11-31, 2014.

LATOUR, B.; WOOLGAR, S. Laboratory Life: The construction of scientific facts. 
Princeton: Princeton University Press, 1986.

LIMA, N.; VAZATA, P.; MORAES, A.; OSTERMANN, F.; CAVALCANTI, C. Educação em Ciências nos Tempos de Pós-Verdade: Reflexões Metafísicas a partir dos Estudos das Ciências de Bruno Latour. Revista Brasileira de Pesquisa em Educação em Ciências, v. 19 (0 SE-Artigos), 2019.

LIMA, N. W.; OSTERMANN, F.; CAVALCANTI, C. J. de H. Física Quântica no ensino médio: uma análise bakhtiniana de enunciados em livros didáticos de Física aprovados no PNLDEM 2015. Caderno Brasileiro de Ensino de Física, v. 34, n. 2, p. 435-459, 2017.

LIMA, N. W.; SOUZA, B. B. de; CAVALCANTI, C. J. de H.; OSTERMANN, F. (2018). Um Estudo Metalinguístico sobre as Interpretações do Fóton nos Livros Didáticos de Física Aprovados no PNLDEM 2015: Elementos para uma Sociologia Simétrica da Educação em Ciências. Revista Brasileira de Pesquisa em Educação em Ciências, v. 18, n. 1, p. 331-364.

MCINTYRE, L. Post-Truth. Cambridge: MIT Press, 2018.

MOURA, C. B. O Ensino de Ciências e a Justiça Social: questões para o debate. Caderno Brasileiro de Ensino de Física, v. 36, n. 1, p. 1-7, 2019.

MOURA, C. B. de; GUERRA, A. Cultural History of Science: A possible path for discussing scientific practices in Science Teaching? Revista Brasileira de Pesquisa em Educação em Ciências, v. 16, n. 3, p. 749-771, 2016.

NASCIMENTO, M. M.; CAVALCANTI, C.; OSTERMANN, F. Uma busca por questões de Física do ENEM potencialmente não reprodutoras das desigualdades socioeconômicas. Revista Brasileira de Ensino de Física, São Paulo, v. 40, n. 3, e3402, p. 18, 2018.

NASCIMENTO, M. M. O acesso ao ensino superior público brasileiro: um estudo quantitativo a partir dos microdados do Exame Nacional do Ensino Médio. 2019. 292p. Tese (Doutorado em Ensino de Física) - Instituto de Física, Universidade Federal do Rio Grande do Sul, Porto Alegre. Disponível em:

<http://hdl.handle.net/10183/188431>. Acesso em: 10 nov. 2019.

NASCIMENTO, M. M.; LIMA, N. W.; CAVALCANTI, C. J. de H.; OSTERMANN, F. Cultura política, desempenho escolar e a Educação em Ciências: um estudo empírico à luz de Pierre Bourdieu . Ciência \& Educação, v. 25, n. 2, Bauru, 2019. 
OXFORD DICTIONARY. Oxford Dictionary 2016 word of the year. Retrieved September 22, 2018, from <https://en.oxforddictionaries.com/word-of-the-year/word-of-the-year-2016>.

POPPER, K. Conjectures and Refutations: The Growth of Scientific Knowledge. Abingdon: Routledge, 1963.

SANTOS, B. de S. Um Discurso Sobre as Ciências. São Paulo: Cortez, 2008.

SANTOS, B. de S. O Fim do Império Cognitivo: A afirmação das epistemologias do Sul. Belo Horizonte: Autêntica, 2019.

SANTOS, B. de S.; MENESES, M. P. Epistemologias do Sul. Coimbra: Edições Almedina AS, 2009.

SANTOS, A. B. dos. Colonização, Quilombos: Modos e Significações. Brasilia, 2015.

SHAPIN, S.; SCHAFFER, S. Leviathan and the Air-Pump. Princeton: Princeton University Press, 1985.

SHIVA, V. Monoculturas da mente: perspectivas da biodiversidade e da biotecnologia. São Paulo: Gaia, 2003.

SNOW, C. P. The two cultures. Cambridge: Cambridge University Press, 1988.

SOKAL, A. D. Transgressing the Boundaries: Toward a Transformative Hermeneutics of Quantum Gravity. Social Text, v. 46/47, p. 217-252, 1996.

VRIEZE, J. Bruno Latour, a veteran of the 'science wars,' has a new mission. Science, 2017. Disponível em: <https://doi.org/10.1126/science.aaq1805>.

Nathan Willig Lima $^{2}$
Matheus Monteiro Nascimento
Instituto de Física - Universidade Federal do Rio Grande do Sul, RS

Direito autoral e licença de uso: Este artigo está licenciado sob uma Licença Creative Commons.

2 E-mails: nathan.lima@ufrgs.br; matheus.monteiro@ufrgs.br 